\title{
CODES OVER HYPERFIELDS
}

\author{
Surdive Atamewoue Tsafack \\ Department of Mathematics \\ University of Yaounde 1, Cameroon \\ e-mail: surdive@yahoo.fr \\ SELESTin NDJeyA \\ Department of Mathematics \\ Higher Teacher Training College \\ University of Yaounde 1, Cameroon \\ e-mail: ndjeyas@yahoo.fr \\ Lutz StrüngmanN \\ Faculty of Computer Sciences \\ Institute for Mathematical Biology \\ Mannheim University of Applied Sciences \\ 68163 Mannheim, Germany \\ e-mail: l.struengmann@hs-mannheim.de
}

AND

\section{Celestin Lele}

Department of Mathematics

University of Dschang, Cameroon

e-mail: celestinlele@yahoo.com

\begin{abstract}
In this paper, we define linear codes and cyclic codes over a finite Krasner hyperfield and we characterize these codes by their generator matrices and parity check matrices. We also demonstrate that codes over finite Krasner hyperfields are more interesting for code theory than codes over classical finite fields.
\end{abstract}

Keywords: hypervector space, hyperring, hyperfield, linear code.

2010 Mathematics Subject Classification: 20N20, 54B20, 94B05. 


\section{REFERENCES}

[1] R. Ameri and O.R. Dehghan, On dimension of hypervector spaces, European J. Pure Appl. Math. 1 (2008) 32-50.

[2] P. Corsini and V. Leoreanu, Applications of Hyperstructure Theory (Kluwer Academical Publications, Dordrecht, 2003). doi:10.1007/978-1-4757-3714-1

[3] B. Davvaz and A. Koushky, On hyperring of polynomials, Ital. J. Pure Appl. Math. 15 (2004) 205-214.

[4] B. Davvaz and V. Leoreanu-Fotea, Hyperring Theory and applications (International Academic Press, USA, 2007).

[5] B. Davvaz and T. Musavi, Codes over hyperrings, Matematički Vesnik 68 (2016) $26-38$.

[6] F. Galand, Construction de codes $\mathbb{Z}_{p^{k}}$-linéaires de bonne distance minimale et schémas de dissimulation fondés sur les codes de recouvrement (Ph.D Thesis, Université de Caen, 2004).

[7] S. Jančic-Rašović, About the hyperring of polynomial, Ital. J. Pure Appl. Math. 21 (2007) 223-234.

[8] M. Krasner, A class of hyperrings and hyperfields, Internat. J. Math. and Math. Sci. 6 (1983) 307-312. doi:10.1155/S0161171283000265

[9] F.J. MacWilliams and N.J.A. Sloane, The Theory of Error-Correcting Codes (NorthHolland, Amsterdam, 1977).

[10] F. Marty, Sur une generalization de la notion de groupe, $8^{\text {iem }}$ Congres Math. Scandinaves, Stockholm (1934) 45-94.

[11] S. Roy and T.K. Samanta, A note on hypervector spaces, arXiv:1002.3816v3 [math.GM].

Received 8 September 2016

Revised 15 June 2017

Accepted 23 June 2017 